\title{
MÚSICA E MAGIA NA FILOSOFIA GREGA
}

ANTIGA

\author{
Cynthia Gusmão \\ FFLCH-USP \\ cygusmao@uol.com.br
}

RESUMO: A filosofia antiga da música grega desenvolveu-se em conexão com a matemática e acústica desde o pitagorismo, que, por sua vez desenrolou-se num contexto ritualístico, mágico e simbólico. O modelo de harmonia universal da ciência pitagórica fez com que ela se expandisse em muitas direçôes, da astronomia à medicina. A obra de Platão reelaborou parte do pensamento musical pitagórico e examinou também a influência da música no ethos humano, tema que foi aprofundado por Aristóteles. O surgimento da abordagem aristoxeniana provocou uma reorganização do campo da investigação musical, criando um domínio específico da música.

PALAVRAS-CHAVES: música, natureza, magia, pitagorismo, Platão, Aristóteles, Aristóxeno, harmônica.

MUSIC AND MAGIC IN ANCIENT GREEK PHILOSOPHY

ABSTRACT: The ancient philosophy of greek music evolved in connection with mathematics and acoustics since the pythagorism, that developed in a ritualistic, magic and symbolic context. The universal harmony model of pythagorean science pushed its expansion in many directions, from astronomy till medicine. The work of Plato worked on part of the pythagorean thinking and examined also the influence of music in human beings, theme that was deepened by Aritstotle. The appearance of aristoxenian approach caused a reorganization of the musical Field, creating musical specific domain.

KEYWORDS: Music, nature, magic, pythagoreanism, Plato, Aristotle, Aristoxenus, harmonics. 
1. "As tribos dos medas são as seguintes: os busos, os paretacenos, os estrúcatos, os arizantos, os búdios e os magos" (HERÓDOTO, 1985 , p. 53)

\section{INTRODUÇÃO}

A música ocidental é marcada pela justaposição de abordagens míticas, técnicas, estéticas e científicas. Poderíamos acrescentar a abordagem mágica, mas a magia, que denota o encantamento, pode ser considerada a própria razão de ser da música e, de Oriente a Ocidente, os humanos produziram música para os mais variados fins.

$\mathrm{Na}$ acepção atual, a magia é tida como uma arte ou uma técnica capaz de produzir efeitos extraordinários, às vezes chamados de sobrenaturais. O termo mágos é relacionada a uma tribo dos medas na História de Heródoto ${ }^{1}$. Os magos medas eram chamados a interpretar sonhos e oficiar cultos e disputaram o poder com o rei persa Cambises (529-522 a.C.), tendo chegado a usurpar seu trono, sendo em seguida massacrados pelas forças reais (HERÓDOTO, 1985, p.169-171).

De acordo com Lloyd (1979, n. 20, p. 13), "no século V a.C. a palavra magos e suas derivadas começaram a ser utilizadas pejorativamente em associação com palavras como charlatães ou vagabundos". Contudo, se investigamos o campo harmônico da raiz indo-europeia> mag vemos que ele está associado a ideias de amassar, cozinhar, modelar, ligando-se a elementos terapêuticos e alimentares. Magos era o nome de um emplastro usado na medicina, maguis, uma massa de cereais e magueireion, a cozinha. Platão (427-347 a.C.), na obra Político, utiliza o termo magueutike como uma tekne relacionada a produção de fármacos, mais especificamente, antídotos (apud BAILLY, 1963, p. 1214-1215). É possível concluir então que na Antiguidade grega o termo magia esteve associado tanto às práticas dos magos e seus sortilégios - maguemas - quanto a formas de trabalhar elementos da natureza para tirar dela determinadas qualidades.

A natureza (physis) foi objeto de reflexão e de indagação dos filósofos que convencionamos chamar de pré-socráticos. Eles investigaram os seus princípios modulando a abordagem mítica e a intermediação direta de deuses, concebendo-a a partir de elementos como água, fogo, ar, ou de pares como quente/frio, denso/rarefeito. Um conceito recorrente é o de harmonia e, nesse sentido, um dos fragmentos mais famosos é o de Heráclito de Éfeso (c.535-475 a.C). Nele, o equilíbrio do mundo oculta uma tensão subjacente: "não compreendem como o divergen- 
te consigo mesmo concorda; harmonia de tensóes contrárias como a do arco e da lira" (Frag. B 51, p. 90).

Para outro filósofo pré-socrático, Empédocles de Agrigento (c. 490-435 a.C.), a harmonia era um princípio de coesão da natureza e tinha seu oposto em neikos, princípio de separação e destruição. A natureza ora misturava ora separava as quatro "raízes": terra, água, fogo e ar. A teoria física de Empédocles, ou teoria dos quatro elementos, teve uma longa trajetória no pensamento ocidental. Ela pode ser considerada a primeira formulação clara da ideia de uma substância, ou um elemento, a partir do qual outras partes da natureza poderiam ser investigadas.

Contudo, além da teoria física do poema Sobre a natureza (Peri physeos), Empédocles escreveu Purificaçôes (Katharmoi), poesia repleta de concepções mágicas. Apesar de que, como diz Lloyd, a partir dessa obra não é possível saber:

(...) se Empédocles sustenta que o conhecimento do homem sábio o habilita a suspender as leis naturais (para realizar milagres) ou se o homem sábio meramente explora os poderes ocultos da natureza a fim de produzir efeitos que são contrários a ela, não no sentido do sobrenatural, mas do extraordinário (LLOYD, 1979, p. 35).

\section{A CONCEPÇÃO MUSICAL DA NATUREZA}

A ideia de uma força oculta inscrita na natureza está presente na concepção desenvolvida pelos pitagóricos, que tomaram os números como princípio originário. Essa concepção de ordem invisível ganha uma força monumental quando ela se torna audível, a partir da tradução dos intervalos musicais fixos da música grega em razões numéricas $2: 1$, a oitava; 3:2, a quinta; e 4:3, a quarta ${ }^{2}$. Na verdade, essa pode ser considerada a primeira lei quantitativa da ciência - da acústica e da física matemática: a proporcionalidade inversa entre a altura e o comprimento de uma corda vibrante. Para os pitagóricos, o que importava é que ela comprovava a existência de um entrelaçamento harmônico entre os quatro primeiros números inteiros na natureza. A figura de Pitágoras é sempre relacionada às ciências exatas enevoando a lembrança de que os pitagóricos tinham vínculos com ideias órficas e com práticas que Burkert chamou de "xamânicas", emprestando o termo
2. Segundo Delatte (1974, p. 258), a atribuição desse feito a Pitágoras é dada não só por seus seguidores, mas também por representantes de outras escolas. 
3. Ver, a respeito disto, Burkert, 1972, p. 162. da língua tunguse da Sibéria ${ }^{3}$. Em sua obra clássica sobre o pitagorismo, o autor comenta:

(...) as fontes mais antigas mostram Pitágoras, diferente de Orfeu, como uma personalidade tangível do período histórico [e não mitológico como Orfeu], mas suas doutrinas são conectadas e até mesmo idênticas. Não há sustentação nessas fontes para as tentativas modernas de ver uma diferença de doutrina entre o orfismo e o pitagorismo antigo. É muito fácil noções modernas virem se intrometer. Se alguém acredita, como Nietzsche, numa oposição primordial entre "apolíneo" e "dionisíaco" então Pitágoras e o orfismo devem se manter na mesma relação polar; e se sob a influência das evidências posteriores, alguém vê a filosofia do número e a fundação das ciências exatas como um ingrediente essencial do pitagorismo, a antítese apolínea e dionisíaca cabe muito bem. Mas devemos ter em mente que os gregos pensavam em Apolo e Dioniso como irmãos; a suposta diferenciação clara entre pitagorismo e orfismo simplesmente não é atestada nas antigas fontes (BURKERT, 1972, p. 132).

Max Weber (1995, p. 53-54) tratou a abordagem pitagórica da música como o preâmbulo do seu processo de racionalização. O sociólogo alemão observou que "o fenômeno da mensurabilidade dos intervalos 'justos' [leia-se consonantes] foi, uma vez reconhecido, de extraordinária impressão sobre a imaginação, como demonstra a imensa mística dos números ligada a isto" (WEBER, 1995, p. 85). É importante lembrar que esse impulso racional a que se refere Max Weber vinculava-se a um discurso sagrado e de caráter simbólico, pois a descoberta das razóes numéricas ocorreu no contexto de um pensamento que se processava por analogias e símbolos para suas explicações. Por exemplo, o princípio organizador do cosmo era expresso pela tetraktys, figura formada por dez pontos dispostos em pirâmide. A soma dos quatro primeiros números, resultando no número dez, fazia dele um número perfeito. Na natureza, as coisas estariam dispostas em conjuntos de quatro. Esses números, e somente eles, formavam as razões das consonâncias do sistema musical grego, cuja base material era o tetracorde. 


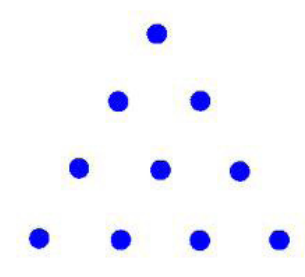

O historiador da matemática Carl Boyer comenta que, para os antigos gregos, a noção de relação entre dois números era diferente daquela existente nas matemáticas egípcia e babilônica em que os dois números indicavam frações ou divisões de um todo. $\mathrm{Na}$ aritmética grega, eles eram vistos como uma razão, ou seja, uma relação entre números inteiros: “(...) um tal ponto de vista, que focaliza a atenção sobre a conexão entre pares de números, tende a pôr em relevo os aspectos teóricos do conceito de número e a reduzir a ênfase no papel do número como instrumento de cálculo ou de aproximação de medidas" (BOYER, 1999, p.36). A matemática grega desenvolveu-se de maneira extraordinária. Mas diferente de Tales de Mileto, outro pai da matemática, Pitágoras esteve associado a uma sabedoria, da qual a música foi a mensageira, ligando-o diretamente a Orfeu.

Diferente de outros pré-socráticos, que buscaram uma substância primordial, os pitagóricos conceberam um princípio imaterial, além disso, com forte potencial de organização hierárquica. Ao encontrar padrões numéricos simples de articulação entre o visível e o invisível (por exemplo, corda/som), eles criaram uma forma sintética de conhecimento da natureza. A primeira fonte escrita que chegou até nós dessa protociência pitagórica foram os fragmentos do livro Sobre a natureza, de Filolau de Crotona (470-385 a.C.). A obra é o testemunho do nascimento dessa ciência: “(...) pode-se ver a natureza do número e sua potência em atividade, não só nas (coisas) sobrenaturais e divinas, mas ainda em todos os atos e palavras humanos, em qualquer parte, em todas as produções técnicas e na música” (Frag. B 11, p. 257). A partir desse modelo de harmonia universal, o pitagorismo expandiu-se a muitos outros domínios como a astronomia, a medicina e a arquitetura.

Um dos casos mais interessantes da presença do pitagorismo na arquitetura grega é o famoso anfiteatro de Epidauros, situado no templo de Asclépios, deus da saúde e da medicina. 
4. Na proporção áurea o todo está para a parte maior, assim como esta última está para o todo (Proposição VI.36 de Euclides, Os Elementos).
5. Jâmblico e Porfírio relatam a crença pitagórica de que a música era boa para saúde (ver, a respeito disto: LLOYD, 1979, p.
De acordo com o cenógrafo grego Vovolis (2000, p.79), sua construção está baseada numa proporção aritmética especial, a seção áurea, tal como desenvolvida pela escola pitagórica ${ }^{4}$. Assim, a relação entre o número de fileiras de assentos em Epidauros, acima (34) e abaixo (21) do corredor central e o conjunto total formaria uma proporção áurea 55:34::34:21, fazendo com que o imenso anfiteatro apresentasse visibilidade e acústica perfeitas.

Vitrúvio, autor romano do século I d.C., considerava que o arquiteto deveria conhecer música "para dominar as suas leis harmônicas e matemáticas" (Vitrúvio, 2006, p.33). Ele dedicou vários capítulos do Livro V de seu Tratado de arquitetura à construção dos teatros. $\mathrm{O}$ arquiteto propõe a colocação de vasos de bronze nas laterais dos teatros para aperfeiçoar a qualidade de timbre da voz. Os artefatos deveriam estar em proporções matemáticas entre si, levando em conta o tamanho do teatro:

De acordo com esses princípios, fazem-se vasos de bronze proporcionalmente à grandeza do teatro, devendo ser fabricados de modo que ao serem tocados produzam entre si sons desde o diatessaron, diapente, e, sucessivamente até ao disdiapason (oitava dupla). Seguidamente, construir-se-ão celas entre os assentos do teatro sendo os vasos aí colocados segundo uma disposição musical, de modo a não tocarem nenhuma das paredes (VITRÚVIO, 2006, p. 185).

Em Epidauros, o plano horizontal da orquestra está baseado no pentagrama, figura que representava saúde para os pitagóricos. A medicina foi um dos campos mais interessantes de disputa entre os procedimentos mágicos e empiristas, que desafiavam os limites entre o natural e o extraordinário - ou sobrenatural. Alguns autores do corpus hipocrático invocavam os deuses para auxiliar a sua prática e a eficácia das preces, dos conjuros e dos amuletos eram defendidas ou combatidas. No século II, o médico Galeno buscou explicar os efeitos da música na arte médica, ideia que já estava presente entre os pitagóricos $^{5}$. Na obra do médico Alcméon (c. 560-500 a.C.), que teria sido contemporâneo do próprio Pitágoras, está elaborada uma teoria da desarmonia como causa das enfermidades (HUFFMAN, 2005, p.22).

Como mostra Burkert, no estudo dos mais antigos documentos, Pitágoras é apresentado como tendo o domínio da 
qualidade mágica da música e neles a teoria dos números é distinta da interpretação que será dada pela filosofia platônica. De qualquer modo, a tradução de um dado da percepção humana, as consonâncias, em números inaugurou uma via em que os tons foram colocados em alto relevo, destacados dos elementos da dança, da poesia, da performance, do timbre dos instrumentos, do ritmo e das circunstâncias de realização, além de tornar-se um campo filosófico e científico. Ao salientar o parâmetro da altura musical, as distâncias intervalares e os modos adquiriram um poder especial. As conexôes entre os modos musicais e os aspectos do comportamento, ou do ethos, serão tema da filosofia tanto de Platão quanto de Aristóteles.

\section{O ethos musical em Platão}

$\mathrm{Na}$ Grécia antiga, além da música ter sido praticada como forma de entretenimento, ela foi utilizada como uma ferramenta do Estado na educação de seus cidadãos, que aprendiam na juventude a cantar acompanhando-se da lira. Seu papel era fundamental nas festividades cívicas e religiosas e havia uma música feita para os deuses e outra para os mortais. Nessas tipologias, as relações costumavam ser estabelecidas entre um estilo melódico e um aspecto moral, associando também instrumentos que deveriam ser utilizados em cada ocasião. A tipologia dos instrumentos variava de acordo com sua tessitura, sua capacidade de ressonância, seu timbre, sua penetração sonora e ainda com sua origem histórica e mítica.

As afinações dos instrumentos distinguiam os modos musicais e, em alguns casos, a terminologia relacionada a elas designava características desses modos; como afinação tensa (esticada) e relaxada (solta), termos que podiam se referir tanto a um estado de espírito quanto ao ponto de tensão de uma corda em um instrumento.

As correspondências entre música e disposições anímicas foram organizadas pelo músico ateniense Damon, conselheiro de Péricles, estadista da metade do século V a.C.. Péricles foi grande incentivador das artes e, de acordo com Plutarco, foi o responsável pela construção do Odeon, uma arena dedicada especialmente à música, para as festas dedicadas à deusa Atena, chamadas de Panatenéias ${ }^{6}$. Pouco restou da obra de Damon, exceto o discurso Areopagiticus, no qual defende que 
6. Ver, a respeito disto: HAVELOCK, 1994, p. 42, n.29. o Areópago, conselho de membros da aristocracia ateniense, deveria ser o guardião das leis e bons costumes da cidade. $\mathrm{E}$ isso deveria ser realizado por meio da música que, ao influenciar a alma humana, afetava a alma do Estado. Damon é referido algumas vezes por Sócrates na República: "Devemos ser cautelosos acerca de mudar para um novo tipo de música, pois isso arriscaria uma mudança total. Os modos (tropoi) da música nunca são mudados sem que se mudem as maiores leis fundamentais (nomoi) do Estado, como disse Damon, e eu concordo (Rep., IV,424c,3-6).

Tal como Dámon, Platão associava physis e nomoi, mas essas doutrinas não eram aceitas tacitamente por todos os filósofos. Diógenes Cínico (cb.413-323 a.C.) dizia que "as pessoas poderiam afinar as cordas da lira e ainda assim ter dissonâncias na alma" (apud SCHUELLER, 1988, p. 26). Em 1905, foi encontrado um papiro numa tumba egípcia na cidade de Hibeh com fragmentos de textos possivelmente do sofista do século V a.C., Hípias de Elis. De acordo com Schueller, Hípias:

(...) não aceitava que a música pudesse expressar os atributos de objetos naturais como o louro (consagrado a Apolo) ou a hera (consagrada a Dioniso). Para ele, a lei natural era uma coisa e a lei feita pelos homens, outra. A melodia enarmônica, ele afirmava, não "fará seus partidários mais corajosos que o cromático os faria covardes" (SCHUELLER, 1988, p. 29).

Hípias foi figura central em dois diálogos platônicos, provavelmente espúrios. Mas certamente as noçóes ligadas ao ethos grego foram preservadas pelos antigos, mais que as objeçóes a elas. E um dos motivos desse sucesso foi a tarefa empreendida por Platão de demonstrar a validade das teorias de Damon a partir da harmonia pitagórica.

Como assinalado anteriormente, os tons musicais ganharam importância nas investigações da ciência grega, a partir de sua expressão matemática no âmbito da escola pitagórica. Diversas culturas conceberam a música como força mágica, mas entre os gregos essa potência ganhou uma especificidade na medida em que sua tradução numérica, correspondente aos tamanhos de cordas, denotava um conhecimento de uma ordem intrínseca, ou oculta, na natureza e, possivelmente, para 
além dela. Esse será um elemento crucial para a abordagem platônica do ethos musical, que seguiu por duas vias.

A primeira via estava ligada à noção pitagórica de que as relações harmônicas são os elementos fundamentais da estrutura do universo. Considerando então que a harmonia teria movimentos similares aos da alma, a música teria condições de restaurar a sua consonância interna, e o ritmo igualmente, que advinha da poesia. $\mathrm{O}$ outro aspecto estava na concepção platônica de arte, baseada na sua teoria das formas, que propunha que o mundo das Ideias teria valor primordial: as Ideias são reais e imutáveis e sua apreensão só pode ser feita pela razão, não pelos sentidos, que captam apenas o fenômeno, considerado enganoso.

Desse modo, na obra República, Platão cria uma hierarquia descendente do filósofo, passando pelo artesão e até o artista. O artista está no mais baixo degrau dessa escada pelo fato de reproduzir a cópia que o artesão faz a partir da Ideia, que é contemplada diretamente apenas pelo filósofo. Nas primeiras seçôes do livro X, Platão examina o papel dos pintores, dos poetas, dos autores de tragédia e comédia, mas não inclui em seus comentários os músicos. Isso levou alguns autores a considerar que, para o filósofo grego, a música seria diferente, por ocupar uma posição intermediária entre as Ideias e o fenômeno. Segundo Dahlhaus/Katz, para Platão:

(...) a música é diferente das outras artes em sua posição ética porque tem uma ligação especial com o mundo das Ideias. Desde Pitágoras, a música estava relacionada à metafísica. Assim também em Platão. Desse modo, enquanto ele mantém que seria necessário para a música estar combinada às palavras que imitam as Ideias — pois os sons sozinhos são meras sensações (Rep. II, 398) — os sons em si mesmos, desacompanhados das palavras, eram a representação primordial da Ideia e um objeto elevado de contemplação (Rep. VII, 529-532) (PLATÃO, 1987, p. 9).

Lembremos que o tom musical também é produzido nos instrumentos, logo, a música instrumental deveria ter lugar de honra para Platão, o que de modo algum é explicitado pelo filósofo. Contudo, ao estabelecer que os tons musicais conectam-se ao aspecto metafísico da realidade, que por sua vez é considerada a verdadeira, Platão confere a eles um poder 
7. Claudio Monteverdi (1567-1643) no "Prefácio" dos Madrigais guerreiros e amorosos, de 1638, afirma que se inspirou nessas linhas da República de Platão para criar o stilo concitato. Apud Strunk/ Treitler, 1998, p. 666. primordial. Ele legitima, por meio de uma explicação metafísica, as implicações éticas da música.

Tanto na República (III, 398-403) quanto em Leis (III, 700 a-e), cujas obras tratam da música no contexto de uma política de Estado, Platão define os estilos melódicos, ou modos, que deveriam ser banidos: o lídio, por expressar tristeza, e o jônio, por levar à indolência; e ele indica os dois modos que deveriam ser mantidos e encorajados. Um deles é o dórico, "uma harmonia que imita as expressões e os acentos de um homem corajoso na batalha" (Rep., III,399a,6-8)..$^{7}$ O outro é o frígio, escolha que será alvo da crítica de Aristóteles (384-322 a.C.), como será mostrado adiante.

Está claro que os tons musicais apenas não constituíam a música grega como um todo, que era uma arte da performance e englobava a poesia e a dança. Mas Platão insiste na contraparte metafísica dos tons. Como sublinha Mathiesen:

Os escritos de Platão nos recordam uma vez mais que todas as manifestações práticas da música formam apenas uma parte do conceito grego de música. Sendo tanto uma arte e uma ciência, a música ocupava um lugar proeminente na vida diária não apenas porque ela era prazerosa e valiosa socialmente, mas também porque incorporava princípios universais mais amplos e servia de veículo para uma compreensão mais sofisticada (MATHIESEN, 1998, p. 5).

A conexão entre a música e a astronomia também forneceu uma provisão considerável de explicaçóes e motivos para a proposta de poder encantatório e educativo da música. $\mathrm{O}$ filósofo afirma, no Livro VII da República, que as duas ciências apresentavam movimento harmônico: "tal como os olhos fixam-se na astronomia, assim os ouvidos fixam-se no movimento harmônico; essas duas ciências são irmãs, assim dizem os pitagóricos, e nós concordamos" (530d). Os astros descreveriam o movimento visível e a música, o audível. Portanto os tons, assim como os planetas, influenciariam a natureza anímica humana.

O modelo de harmonia universal dava fundamento à conexão entre música e astronomia. Filolau havia desenvolvido uma astronomia centrada na noção de intervalos musicais, que será retomada depois por Platão no Timeu (35b-36c) na passagem em que o filósofo ateniense descreve a escala musical como um princípio amalgamador do cosmos. 
Podemos especular se a relação entre música e astronomia e a noção de harmonia das esferas, tal como aparece na narrativa fantástica do soldado armênio Er, no décimo livro da República (614b-617d) de Platão, não foi responsável por lançar na imaginação ocidental as sementes da ideia de polifonia. Nesse mito, criado pelo autor, cada planeta é representado por uma sereia que emite um tom da escala musical, polifonicamente, trazendo a música, arte do tempo, para a simultaneidade do espaço. Essa imagem terá uma força duradoura e, no século II d.C., Claudio Ptolomeu no livro III da sua obra Harmônica, fará conexões entre aspectos planetários e intervalos musicais. Contudo, as relaçôes entre modos musicais e planetas só vão aparecer de maneira explícita, mais tarde, nos escritos islâmicos medievais.

Platão observa atentamente os instrumentos, pois se os instrumentistas dominavam as poderosas harmonias, eles tinham a habilidade e o conhecimento para abalar a estrutura do Estado, coisa que o preocupava. O aumento da complexidade da música grega relacionava-se ao avanço das técnicas de construção de instrumentos, assim como à lenta e gradativa aceitação das apresentações puramente melódicas, como sugere a criação do ágon musical de Péricles ${ }^{8}$.

Para Platão, a sofisticação dos estilos melódicos deveria ser rejeitada e a simplicidade exaltada como um valor primordial. $\mathrm{Na}$ República, Sócrates pergunta a seus interlocutores:

— Então, nem os instrumentos de muitas cordas nem o de muitas harmonias devemos querer em nossas cançôes e melodias?

- Para mim não, evidentemente.

- Sendo assim, não devemos encorajar os construtores de trígonas, de péctis e todos os instrumentos de muitas cordas e muitas harmonias.

- Claro que não.

- E os construtores de aulos e os auletistas devem ser acolhidos na cidade? Não acontece dos instrumentos de muitas cordas imitarem as panarmonías do aulos?

— Sim, é evidente.

- Então a ti parece que a lira e a cítara são os instrumentos úteis à cidade, enquanto que no campo as pessoas devem utilizar a syrinx.

—É o que indicam nossas palavras (Rep., III,399 d-e).
8. Ver, a respeito disto, Havelock, 1994, p. 42, no. 29. 
Platão desgostava da característica do aulos que, como instrumento de palheta, produzia variaçóes tonais sutis e escalas que se expandiam por meio das mudanças de modos resultantes provavelmente do aperfeiçoamento das digitaçôes ou outros procedimentos. De acordo com Platão, as mudanças sucessivas de modos criavam dificuldades de percepção da sua finalidade. Ele criticava os instrumentistas de cordas que começaram a imitar as complexidades dos auletistas. Para Havelock, o motivo da rejeição do auletista adviria da sua gradativa independência do cantor:

Os instrumentos de sopro sempre exigiam que houvesse um artista para recitar e outro para tocar (exceto quando a música se limitava aos interlúdios); (...) Essa situação ajuda a explicar por que, quando a execução musical - em nosso sentido de "musical" - começou a emergir como uma arte autônoma, lá pelos fins do século $\mathrm{V}$ a.C., (quando isso era de esperar, pois a leitura de poesia começava a ter incremento), foi como concerto de aulos que ela apareceu. $\mathrm{O}$ auletista, sempre um indivíduo posto à parte na recitação, começou a apresentar-se por conta própria (HAVELOCK, 1994, p. 26).

A filosofia platônica apresenta fortes argumentos em favor da razão e chama a atenção para a incerteza da experiência sensorial, algo que já estava presente no pensamento de alguns pré-socráticos. Mas, para além disso, ela reflete o universo extremamente sofisticado da música grega da passagem do século V para o IV a.C.

\section{ETHos, PRÁtica E CATARSE NA FILOSOFIA MUSICAL aristoté-} LICA

Aristóteles, no livro VIII da Política, dialoga diretamente com a filosofia da música platônica ao discutir se a música deveria ser incluída na educação dos jovens. Mas ele propóe uma reavaliação da eficácia do poder da música e da sua função.

A indagação aristotélica parte de três funções da música: diversão e relaxamento, passatempo (diagoge) e capacidade de produzir uma qualidade de caráter específica "tal como a ginástica é capaz de produzir uma certa qualidade do corpo" (1339a). Seu método toma as opiniōes comuns como termômetro da verdade, portanto, se todos dizem que a música é 
prazerosa, "seja ela instrumental, ou vocal e instrumental" (1339b), ela de fato diverte, relaxa e é um passatempo. Nesse sentido, a música é ótima para dar aos jovens algo para fazer, de modo que eles fiquem quietos, tal como acontece com "o chocalho de Arquitas, uma boa invenção que as pessoas dão às crianças para que fiquem ocupadas e não quebrem os móveis" (1340b). Além disso, é importante que o jovem aprenda a tocar o instrumento e a cantar, pois "é algo impossível, ou difícil, tornar-se um bom juiz de performances se não tiver participado de uma" (1339b).

Ao investigar se a música alcança e influencia o caráter e a alma, Aristóteles considera novamente o senso comum: "todos, ao ouvirem imitações [musicais], são lançados num estado de sentimento correspondente, mesmo sem o ritmo e a poesia" (Política, 1340a). Mas quais seriam esses efeitos? Ele segue em linhas gerais as direções platônicas quanto ao ethos dos modos, dos ritmos e dos instrumentos, contudo, discorda nas formas de utilização "Aceitamos a divisão de harmonias propostas pelos filósofos em melodias éticas, práticas e entusiásticas mantendo, contudo, que a música não deva ser estudada para se obter um único benefício apenas, mas vários" (Pol.,1341b,33-39).

Aristóteles critica a utilização da música apenas para fins de controle do Estado. Para ele, todos os expedientes da música devem ser utilizados, pois as melodias e os instrumentos servem a vários fins, não a um somente. As três finalidades seriam educar, recrear e produzir a catarse.

É evidente que devemos empregar todas as harmonias, embora não da mesma maneira. Devemos utilizar os modos mais éticos para a educação e os práticos e os patéticos para ouvir quando outros os estão executando, pois qualquer experiência que possa ocorrer em algumas almas é comum a todas, embora em diferentes graus de intensidade - por exemplo, piedade e medo. No caso das paixões entusiásticas, algumas pessoas são afeitas a ela e sob a influência da música sagrada, quando se utilizam melodias entusiásticas, nós as vemos serem lançadas a um tal estado, que é como se tivessem tomado um medicamento purgativo; a mesma experiência deve também ser dirigida aos compassivos e aos medrosos a fim de produzir outros estados emocionais em todos os tipos de indivíduos, e todos devem passar pela catarse e sentir a agradável sensação de alívio; da mesma maneira, os modos 
práticos, que incitam à ação, são um deleite inofensivo às pessoas (ARISTÓTELES, Pol.,1342a,1-18).

Para Aristóteles, o modo dórico, e nenhum outro, deveria ser empregado na educação dos jovens por ser o mais ético de todos, e por sua natureza mediana, que ensinaria a moderação. Isso se deve ao fato do modo dórico ficar na metade do sistema grego, entre o frígio, o lídio e o mixolídio de um lado, e o hipodórico, o hipofrígio e o hipolídio de outro. Para Aristóteles, Sócrates havia errado na República ao recomendar o modo frígio ao lado do dórico para a educação dos cidadãos e simultaneamente rejeitar o aulos, pois:

(...) o modo frígio, dentre as harmonias, tem o mesmo efeito que o aulos dentre os instrumentos, ambos são orgiásticos e patéticos. Isso fica evidente na poesia no caso do ditirambo que é admitidamente um metro frígio; e os especialistas dão inúmeras provas disto, particularmente o fato de que Filoxenus ao tentar compor um ditirambo, Os Misios, utilizando o modo dórico, não ter conseguido (ARISTÓTELES, Pol.,1342 b, 6-10).

Aristóteles argumenta em favor de harmonias que haviam sido excluídas por Sócrates, ou Platão, como a lídia, por ser um modo relaxado. Para ele, os idosos serão beneficiados com esse tipo de melodia. Em resumo, não se deve excluir nenhum modo, mas adequá-lo à idade, ao tempo e ao lugar. O jovem deve ser direcionado à educação musical, mas desde que se saiba o que é adequado ou não: "fica claro que nós temos que estabelecer três cânones para guiar a educação: moderação, possibilidade e adequação" (Pol., 1342a,14-15). E, no caso dos instrumentos, deve-se observar quais deveriam ser utilizados:

Os auloi não devem ser apresentados na educação, nem outro instrumento profissional (téknikon órganon), como a cítara ou outro desse tipo, mas apenas aqueles instrumentos que tornarão os alunos atentos às aulas e ao próprio treinamento musical. $\mathrm{O}$ aulos não é edificante (éthicon), mas orgiástico, de modo que ele só deve ser empregado em situações de catarse e não de instrução. E gostaríamos de acrescentar que o aulos tem o inconveniente adicional de evitar o emprego da palavra (ARISTÓTELES, Pol.,1341 a,17-26). 
A questão da proeminência da música vocal sobre a instrumental, conforme já exposta, permanecia em aberto na obra platônica na medida em que as relações harmônicas mantinham a conexão com o mundo das Ideias; o fato de Platão condenar a utilização dos instrumentos não significa que não lhes atribuísse poder, ao contrário9* . Já Aristóteles apoia a música instrumental desde que na circunstância apropriada, pois, no caso da educação dos jovens, além do aulos: “(...) outros instrumentos são desaprovados como a péctis, o barbitos e os instrumentos feitos para dar prazer àqueles que os tocam: a heptágona, a trígona e a sambuca, que requerem destreza manual" (ARISTÓTELES, Pol., 1341a,39-1341b,1).

A trígona e a sambuca eram instrumentos da classe dos psaltérios, em geral associada aos cientistas musicais do século VI a.C.. Algumas representaçóes os relacionam à deusa Ártemis e, de acordo com Mathiesen, os dois instrumentos parecem ter sido exclusivos das mulheres (1999, p. 270). A trígona está presente em várias representaçôes de vasos gregos, diferente da sambuca, que é menos representada, mas recebe uma referência no Deipnosophista de Atheneu (633f-634b). Segundo esse autor do século II d.C., a sambuca é um instrumento bastante agudo, com o formato de uma nau e havia sido descrita no primeiro livro de mecânica de Moschos como um mecanismo romano. Ela teria o cavalete em pé com as cordas presas à base como as velas de um navio. Atheneu cita um trecho das Histórias de Políbio em que há essa sugestão de analogia: "Marcelo, rendido no cerco de Siracusa pelo maquinário de Arquimedes, disse que Arquimedes havia afundado os navios no mar e que as sambucas, insultadas como em uma festa, caíram em desgraça" (apud MATHIESEN, 1999, p. 279). Além do fato de instrumentos como a trígona e sambuca exibirem muitas cordas, o que estimulava o virtuosismo, a sua condição de instrumentos estrangeiros sempre pesou na sua rejeição em Atenas.

Outras obras do corpus aristotelicum são estudos sobre música e som, entre elas está o Livro XIX de Problemas em que são levantadas questões sobre o ethos musical:

Por que os ritmos e as melodias que são somente sons, assemelham-se a caracteres morais, mas não os sabores, nem as cores e nem os odores? Será porque são movimentos também as ações?
9. Cf. Platão,Leis,II, $669 \mathrm{c}-670 \mathrm{a}$. 
E a ação já encerra um caráter moral, mas os sabores e as cores não atuam do mesmo modo? (ps-Arist, Probl.,XIX, 29).

A noção de movimento é central na filosofia aristotélica e Aristóteles a preserva na música, mas afasta a ideia da sua influência no comportamento de qualquer relação com a astronomia, distanciando-se da visão platônica. As objeções de Aristóteles ao pitagorismo referiam-se à metafísica e à astronomia. No que tange às razóes numéricas musicais, ele estava de acordo que elas fossem os princípios da ciência da música, como afirma nos Analíticos posteriores: "O que é a consonância? É a razão dos números no agudo e no grave. Por que o agudo harmoniza com o grave? Porque uma razão aritmética situa-se entre os dois" (90 a, 19-22).

De qualquer modo, a refutação do modelo astronômico pitagórico representou uma ruptura com algumas ideias de seu professor, Platão, mas caberá a seu aluno Aristóxeno de Tarento (c. 360-c.300 a.C.) desafiar as relações entre música e pitagorismo.

\section{O ESTABELECIMENTO DA CIÊNCIA HARMÔNICA E DA TEORIA MU-} SICAL

Aristóxeno, em sua obra Elementos de harmônica, rejeita tanto a aplicação da matemática quanto os experimentos acústicos para a compreensão da música, aproximando-a mais de uma tekne (ars) que de uma episteme (scientia). Mas não é assim que enuncia a sua intenção, que diz ser a de delimitar uma ciência rigorosa, melos episteme, ou harmônica.

Para isso, toma como primeiro elemento a percepção musical, tal como ela se apresenta de maneira inequívoca ao ouvido: “(...) para o músico, a exatidão da percepção sensível está quase na ordem de um princípio. Tanto é verdade que é impossível, quando não se tem o ouvido treinado, falar corretamente sobre aquilo que não se percebe" (Elementos de harmônica, B-33[21-26]). Assim, a classificação dos intervalos em consonâncias ou dissonâncias não irá depender de nenhuma aritmética, mas daquilo que Aristóxeno nomeia propriedade da oitava. Max Weber chamou essa propriedade de "identidade em outro grau": 
(...) o acompanhamento de vozes em oitavas (vozes de homens e vozes de meninos ou mulheres) é um fenômeno universalmente difundido, tendo sido familiar também à Antiguidade. A oitava, ao que parece, é sentida, por toda a parte onde é encontrada, como identidade em outro grau (WEBER, 1995, p. 105).

A propriedade da oitava, para Aristóxeno, fazia com que qualquer intervalo consonante ao qual fosse acrescentada uma ou duas oitavas se tornasse consonante também. Isso ameaçava a tetraktys pitagórica, pois incluía a quarta+oitava $\left(11^{\mathrm{a}}\right)$ entre as consonâncias. Esse intervalo não podia ser considerado consonante pelos pitagóricos, pois sua razão, 8:3, extrapolava a rigorosa prescrição de utilizar apenas os 4 primeiros números para as razões das consonâncias. Para Aristóxeno, o argumento mágico dos pitagóricos não pertencia à melos episteme.

$\mathrm{Na}$ filosofia aristoxeniana, a prática do músico ocupa o lugar central, mas ela tem dois aspectos: a escuta (akoue) e o discernimento, ou inteligência (dianoia): "é necessário no que se refere à constituição do melos habituar conjuntamente a inteligência e a escuta a julgar bem o que permanece e o que se movimenta" (Elementos de harmônica, B-34[19-21]). No caso dos intervalos, ele defendia que a escuta julgava o seu tamanho e o discernimento as suas funções:

(...) é preciso habituar-se a julgar cada coisa de maneira precisa e não dizer como costumam aqueles que fazem os diagramas: seja esta linha reta! Pois o geômetra não precisa da função da sensação (...) mas mais o técnico ou aquele que trabalha no torno e outras coisas técnicas (Elementos de harmônica, B-33[10-21]).

A coesão e a sustentação do sistema musical aristoxeniano não são dadas pela cosmologia, mas pela estrutura da música, que não tem necessidade de elementos extramusicais para sua ordenação. Sua natureza não tem a ver com a aritmética ou com a produção, emissão, propagação ou audição do som. Ela ocupa um espaço especificamente musical - por que não dizer, artístico. A preocupação de Aristóxeno não é com o som, mas com o tom.

Apesar do alcance da filosofia de Aristóxeno, a teoria aritmético-acústica pitagórica mantinha sua força pujante, o que era realçado pelo caráter sagrado do discurso. Aristóxeno, deslocando a música do edifício da harmonia universal, teria retirado 
10. Ver, a esse respeito, Barker, 2007, p. 55 e Winnington-Ingram, 1968, p. 49. sua capacidade de seduzir e encantar? Seu professor Aristóteles havia recriminado Platão por "usar metáfora poética" na exposição da teoria das formas (Metaf., XIII,1079b,26). Para Aristóteles, a metáfora não deveria ser utilizada pelo filósofo natural, ela só teria lugar na poesia e na retórica. Do mesmo modo, a harmônica de Aristóxeno, sendo uma ciência, deveria usar recursos próprios para a investigação da sua natureza.

Mas existe ordem musical para o tarentino. Os intervalos estão dispostos hierarquicamente, de acordo com a necessidade natural do melos, É desse modo que se estabelecem as notas fixas e móveis formadoras dos gêneros: “a voz segue a natureza em seu movimento e não forma um intervalo ao acaso" (Elementos de harmônica, B-33[10-21]). Os intervalos não são apenas medida, eles requerem uma compreensão da sua lógica musical. Isso é dado pelos conceitos de continuidade e sucessão, que presidem a formação das escalas (systemata). $\mathrm{Na}$ prática, os músicos não se valiam dos systemata, mas dos tono $i$, ou tonalidades.

Muitos autores concordam que essa matéria dos tonoi é uma das mais complicadas da harmônica ${ }^{10}$. Eles estariam ligados aos modos gregos, com seus respectivos nomes étnicos: dórico, frígio, jônio, lídio e variantes. Os tonoi eram objeto da prática de músicos auletistas conhecidos como harmonicistas, que os notavam em diagramas. $\mathrm{O}$ grupo era criticado por Aristóxeno: "a doutrina dos harmonicistas sobre as tonalidades é análoga ao modo como se contam os dias dos meses: assim, por exemplo, quando para os coríntios são dez, para os atenienses são cinco e ainda para outros oito" (Elementos de harmônica, B-37 [14-17]).

A parte que restou da doutrina dos tonoi de Aristóxeno é bastante fragmentária; sendo assim, costuma-se recorrer aos manuais de autores posteriores, especialmente a Introdução à harmônica de Cleônides, provavelmente do séc. II d.C., mas ainda assim ela permanece obscura. É possível que Aristóxeno tenha dado indicaçôes de como empregar os tipos melódicos em seções perdidas de sua obra. $\mathrm{O}$ tarentino certamente sabia que não é necessário pensar em aspectos cosmológicos ou na teoria dos números para se produzir uma música capaz de encantar e seduzir. Ele deixa claro ainda que apenas o estudo da harmônica não basta para alcançar o objetivo final da música: 
Algumas vezes ocorrem erros em duas direções. Por um lado, existem aqueles que pensam que os estudos são algo de suma importância. Dentre estes, alguns não só pensam que tornar-se-ão músicos ouvindo coisas sobre a Harmônica, como (também) tornar-se-ão melhores no que diz respeito ao caráter, entendendo mal as exposições públicas que fizemos a respeito tanto de cada uma das composiçôes melódicas quanto da música como um todo; (demonstrando) o que prejudica as coisas da esfera do caráter e o que aperfeiçoa. Compreendendo isso mal, não entenderam completamente em que extensão a música é capaz de aperfeiçoar. Outros, ao contrário, pensam que (a Harmônica) é insignificante, algo pequeno e desejam ignorar o que quer que seja.

Ficará claro, no decorrer do discurso, que nenhuma destas posições é verdadeira: o estudo nem é passível de ser desdenhado por alguém que tenha inteligência, nem de ser engrandecido como se fosse autossuficiente em relação a tudo como alguns pensam. Como dizemos sempre, muitas outras coisas são necessárias ao músico. O estudo da harmônica é parte do seu domínio, tal como a rítmica, a métrica e a organologia (Elementos de harmônica $\mathrm{B}-31[12-24]-32[1-5])$.

Assim também a capacidade de dizer em que modo está a melodia e a notação musical não faz parte da ciência musical aristoxeniana: "Assim como não é necessário, na métrica, que quem saiba escrever um metro jâmbico conheça perfeitamente o que é o jâmbico, assim também, no melos, não é necessário que quem saiba escrever a melodia frígia, conheça perfeitamente o que seja a melodia frígia" (Elementos de harmônica, B- 39 [11-15]).

Aristóxeno deu à palavra grega melos um sentido especificamente tonal ${ }^{11}$, modificando a concepção anterior que a referia a uma combinação de palavra, ritmo e melodia. Ela é distinta do melos composto ao qual poderíamos incluir elementos de coreografia, e que Platão e Aristóteles mencionaram ao atribuir efeitos da música ao comportamento humano, falando do ponto de vista do ethos musical. Para ele, a força da música estava na sua própria natureza: "nenhuma das coisas sensíveis possui uma ordem tão grande e de tal qualidade" (Elementos de harmônica, A-5 [29-30]).

Winnington-Ingram analisou a questão do ethos na música grega da seguinte forma: Essa concepção de um caráter inerente dos modos não está restrita à Grécia; mas é visível aqui devido 
11. O termo tonal aqui,evidentemente, não refere-se ao sistema tonal que se desenvolveu muito mais tarde no Ocidente, mas apenas ao tom entendido enquanto som de altura definida.

12. Ver, a esse respeito, Huffman, 2008. à fama de alguns autores e à interpretação moral que colocavam no caráter dos modos. (...) É mais pertinente expressar algum ceticismo, se os elementos musicais podem em si mesmos possuir tais caracteres tão marcados. Muitos outros fatores estão em jogo (1968, p.3).

De fato, é necessário atentar para que não haja justaposição de uma concepção de música eminentemente instrumental ao fenômeno do ethos musical da Antiguidade. A música grega antiga era eminentemente vocal - portanto, ligada a um texto poético - e também circunstancial, ou seja, destinada a ocasiões determinadas fazendo com que a utilização de um determinado modo estivesse dentro de um contexto mais amplo de performance.

\section{CONSIDERAÇÕES FINAIS}

Uma característica fundamental da sociedade grega eram os debates públicos, com seus antagonismos e polarizações. Eles aconteciam, por exemplo, nos jogos pan-helênicos que reuniam não apenas competições esportivas, mas de música, teatro e poesia, e palestras sobre vários assuntos, por exemplo, teoria dos elementos ou os constituintes fundamentais do corpo humano (cf. Lloyd, 1987, p. 91). Os cidadãos participavam e as polarizaçóes eram vistas como benéficas. $\mathrm{O}$ caso exemplar é Platão e Aristóteles, professor e aluno, que discordaram em matérias fundamentais.

O antagonismo e a ironia de Aristóxeno em relação aos pitagóricos eram próprios da sua maneira de apresentar o caso. $\mathrm{Na}$ verdade, seu pai foi um conhecido pitagórico e ao quatro obras de Aristóxeno abordaram o tema do pitagorismo: Sobre Pitágoras e seus seguidores, Sobre a vida pitagórica, Preceitos pitagóricos e Vida de Arquitas. Nenhuma sobreviveu completa, mas são encontrados fragmentos delas em autores posteriores, considerados valiosos para o estudo do pitagorismo. Pelo fato de Aristóxeno ter vivenciado de perto o ambiente em que se debatiam tais ideias, alguns estudiosos consideram que seus comentários apresentam uma visão mais próxima da realidade da escola pitagórica do que aquela difundida pelos sucessores de Platão ${ }^{12}$. Já a postura epistemológica aristoxeniana estava em sintonia com o princípio de Aristóteles: se a experiência se 
opõe à teoria, é preciso modificar a teoria. De qualquer modo, a sua ênfase na percepção fará com que ele passe à Idade Média como um pensador que concedia tudo à sensação e nada à razão, como afirma Boécio (480-525/26) na obra Instituições musicais (apud BÉLIS, 1986, p.227 nota 65). O autor romano muito contribuiu para a transmissão de uma apreciação errônea da obra aristoxeniana.

O espaço dedicado à música nas obras dos filósofos gregos não deixa dúvida da sua importância naquela sociedade. Mas é impossível compreendê-la sem enxergar o resistente tecido composto por suas técnicas, ciências e mitos. A música, como em todas as sociedades, participava de seus cultos, como os mistérios de Elêusis, Dioniso ou Deméter. Tales de Mileto dizia que a terra flutuava na água. Por mais que isso nos cause estranhamento, essa afirmação é bastante diferente da ideia de que o mundo era sustentado nos ombros de um deus. Mas o pensamento especulativo não estava em oposição direta aos cultos e mistérios gregos. Pitágoras, um dos pais da matemática ocidental, é também mencionado como um hierofante do culto de Deméter. Aristóteles ressaltou que "aquele que passa pelos mistérios (teloumenoi) devia não aprender, mas "ser afetado", "sofrer" ou "vivenciar" (pathein)" (cf. Burkert, 1991, p. 80). Sócrates, no diálogo platônico Mênon, antes de desenhar a figura do quadrado na areia, para demonstrar que o conhecimento é na verdade uma relembrança, refere-se com respeito aos "homens e mulheres sábios nas coisas sagradas" (81a) e declama um poema de Píndaro dedicado a Perséfone, a filha de Deméter. Como chamou a atenção Lloyd:

Qualquer tentativa de contrastar diretamente como um todo magia e ciência é passível de distorcer a natureza e o objetivo da magia. A magia, como tem sido notadamente argumentado, deve ser vista menos por sua intenção de eficácia do que como afetiva, expressiva e simbólica (LLOYD, p. 6).

No século IX, o filósofo Al-Kindi (801- 873) irá aprofundar as relações entre ciência e música e, ao mesmo tempo, detalhou as forças presentes nas configurações modais, relacionando-as aos planetas. A tradição árabe medieval e os autores gregos renascerão em outros matizes no século XV, por exemplo, na obra do florentino Marsilio Ficino (1433- 
1499). Além dele, o espanhol Bartolomeu Ramos de Pareja (1440-1522), o italiano Franchino Gaffurio (1451-1522) e o alemão Cornelius Agrippa (1486-1535) vão dedicar estudos sobre as conexões entre a harmonia das esferas e os ethoi dos modos, abrindo caminhos para a pratica de uma música efetiva, pronta a refletir as novas ideias de manipulação humana da natureza.

REFERÊNCIAS BIBLIOGRÁFICAS:

ARISTÓTELES. Metafísica. In: Coleção Pensadores. São Paulo: Abril Cultural, 1979.

.Problemas musicais. Trad.: Maria Luiza Roque. Brasília: Thesaurus Editora, 2001.

Posterior Analytics. In: A new Aristotle reader. Ed.: J.L.Ackrill. Oxford: Clarendon Press, 1987, p. 39-59.

ARISTÓXENO. Aristoxeni Elementa Harmonica. Da Rios, Rosetta (Ed.). Roma: Typis Publicae Officinae Polygraphicae, 1954.

ARQUITAS. Fragmentos. Trad. de Ísis L. Borges. In: Coleção “Os Pensadores". São Paulo: Abril Cultural, 1973, p. 260-261.

BAILLY, A. Dictionnaire grec-français. Paris: Hachette, 1963.

BÉLIS, Annie. Aristoxène de Tarente et Aristote: Le traité d'harmonique. Paris: Klincksieck, 1986.

BURKERT, Walter. Antigos cultos de mistério. São Paulo: Edusp, 1991.

Lore and science in ancient pythagoreanism. Cambridge: Harvard University Press, 1972.

DAHLHAUS, Carl e KATZ, Ruth. Contemplating music. Vol.I. Nova York: Pendragon Press, 1987.

DELATTE, Armand. Etudes sur la littérature pythagoricienne. Genebra: Slatkine Reprints, 1974.

DETIENNE, Marcel. A invenção da mitologia. Brasília: José Olympio/Edunb, 1992. 
Euclides. Os Elementos. Disponível em <http://www.perseus. tufts.edu>. Acesso em 02 de janeiro de 2014.

FILOLAU. Sobre a natureza. Trad. de Ísis L. Borges. In: Coleção “Os Pensadores". São Paulo: Abril Cultural, 1973, p. 255-258.

HAVELOCK, Eric. A revolução da escrita na Grécia. São Paulo: Unesp/Paz e Terra 1994.

HERÁCLITO - Fragmentos. Trad. de José Cavalcante de Souza. In: Coleção "Os Pensadores”. São Paulo: Abril Cultural, 1973, p. 79-97.

HERÓDOTOS. História. Brasília: Editora Universidade de Brasília, 1985.

HUFFMANN, Carl. Philolaus. In: ZALTA, Edward N. (ed.), The Stanford Encyclopedia of Philosophy (Summer 2005 Edition). Disponível em: <http://plato.stanford.ed.u/archives/ sum2005/entries/philolaus $>$. Acesso em 04 de setembro de 2009.

LLOYD, Geoffrey E.R. Magic, reason and experience. Studies in the origins and development of greek science. Cambridge: Cambridge University Press, 1979.

The revolutions of wisdom - studies in the claims and practice of ancient Greek science. Berkeley: University of California Press, c1987.

MATHIESEN, Thomas. Apollo's lyre. Nebraska: University of Nebraska Press, 1999.

PLATÃO. Laws. Disponível em: <www.perseus.tuft.edu>. Acesso em 03 de janeiro de 2014.

. La Repubblica. Milão: Mondadori, 1990.

. Meno. Londres: Penguin Classics, 1956.

PTOLOMEU. Harmonics. Trad. Jon Solomon. Londres: Brill, 1999.

SCHUELLER, Herbert. Idea of Music: an introduction to musical aesthetics in Antiquity and the Middle Ages. Michigan: Kalamazoo: Medieval Institute Publications, 1988. 
TREILER, Leo (ed.) Strunk's Source Reading in Music History. Nova York: Norton Company, 1998.

VITRÚVIO. Tratado de arquitetura. Lisboa: IST Press, 2006.

VOVOLIS, Thanos. The voice and the mask in ancient Greece. In: Soundscape. Londres: Wallflower Press, 2007, p.73-82.

WEBER, Max. Fundamentos racionais e sociológicos da música. São Paulo: Edusp, 1995. 